УДК 347.9

DOI 10.17308/vsu.proc.law.2020.1/2405

\title{
ПРОБЛЕМЫ ПРАВОВОГО СТАТУСА ПРОКУРОРА ПО ДЕЛАМ ОБ ОСПАРИВАНИИ НОРМАТИВНЫХ ПРАВОВЫХ АКТОВ И АКТОВ, СОДЕРЖАЩИХ РАЗЬЯСНЕНИЯ ЗАКОНОДАТЕЛЬСТВА И ОБЛАДАЮЩИХ НОРМАТИВНЫМИ СВОЙСТВАМИ: СТАТИСТИЧЕСКИЙ АНАЛИЗ СУДЕБНЫХ ДЕЛ*
}

\author{
А. О. Вифлянцев
}

Национальный исследовательский университет "Высшая школа экономики"

Поступила в редакцию 21 ноября 2019 г.

\begin{abstract}
Аннотация: статья посвящена исследованию правового статуса прокурора с точки зрения его участия в делах об оспаривании нормативных правовых актов и актов, содержащих раздяснения законодательства и обладающих норлативныли свойствали, на основе статистического анализа судебных решений. Рассматриваются сложившиеся в процессуальной науке подходы по проблемам участия прокурора в гражданском процессе. Делаются выводы о тол, что в настоящее вреля как в законодательстве, так и практике назрела необходилость к выработке новых решений и концепций. Предлагается переход к идее «частного принуждения" либо переход $\kappa$ концепиии «прокурор - инструмент по обеспечению баланса публичных и частных интересов".

Ключевые слова: адлинистративное судопроизводство, прокурор, заключение прокурора, статистический анализ.
\end{abstract}

\begin{abstract}
: this article is devoted to the study of the legal status of the attorney general in cases of challenging normative legal acts and acts containing explanations of the legislation and having regulatory properties, based on statistical analysis of court decisions. The author examines the approaches to the problems of the attorney's participation in the civil process and as a result comes to the conclusion that at present both in law and practice there is a need to develop new solutions and concepts of the legal status of the attorney general in cases of challenging normative legal acts and acts containing explanations of the legislation and having regulatory properties. In particular, the author proposes a transition to the concept of "private attorney general" or the transition to the concept of "Prosecutor - a tool to ensure the balance of public and private interests".

Key words: administrative proceedings, the attorney general, powers, prosecutor's decision, statistical analysis.
\end{abstract}

Прокурор занимает особое место в системе государственных органов Российской Федерации, обладая полномочиями во всех видах судопроизводства: в конституционном, гражданском, административном и уголовном.

* Автор благодарит за ценные замечания и критику, высказанную в отношении проекта данной статьи на разных этапах ее подготовки М. С. Павлову.

(C) Вифлянцев А. О., 2020 


\section{Вестник ВГУ. Серия: Право}

В настоящее время прокурор в рамках судопроизводства по делам об оспаривании нормативных правовых актов (данная категория дел с точки зрения действующего закона (от лат. lege lata) служит, прежде всего, защите интересов общества в устранении "некачественных» нормативных правовых актов ${ }^{1}$ ) имеет следующие полномочия: 1) право на подачу административного искового заявления в защиту прав, свобод и законных интересов граждан, неопределенного круга лиц или интересов РФ, субъектов Федерации, муниципальных образований либо в защиту интересов несовершеннолетнего или лица, признанного в установленном порядке недееспособным, на основании которого суд возбуждает производство по делу; 2) право на дачу заключения по административному делу․․

В рамках статистического анализа были рассмотрены только те дела по оспариванию нормативных правовых актов, в которых Судебная коллегия Верховного Суда РФ по административным делам выступала в качестве апелляционной инстанции. Для исследования дел были выбраны следующие критерии: 1) временной критерий-период - 2-е полугодие 2018 г.; 2) инстанционный критерий - анализ дел, рассмотренных в апелляционном порядке. Такие критерии объясняются целями получения данных о позиции прокуратуры в двух инстанциях, а также сравнения позищии суда субъектов и Верховного Суда РФ. Всего Судебной коллегией Верховного Суда РФ по административным делам во втором полугодии 2018 г. в апелляционном порядке было рассмотрено 576 дел $^{3}$. В исследовании было проанализировано 118 дел (более 20 \% от общего числа) ${ }^{4}$. В двух случаях суд апелляционной инстанции принял решение прекратить производство по делу, в одном случае - оставить дело без рассмотрения. В связи с тем что в этих трех решениях спор не был разрешен по существу, данные споры были исключены при статистическом анализе ${ }^{5}$.

$\checkmark$

${ }^{1}$ См.: Ярков В. В., Спицин И. Н. Судебный нормоконтроль в гражданском и арбитражном процессе : современное состояние и пути совершенствования // Вестник Санкт-Петерб. ун-та. Серия: Право. 2018. № 4. С. 554-567.

${ }^{2}$ Кодекс административного судопроизводства Российской Федерации : фе-дер. закон от 8 марта 2015 г. № 21-ФЗ. Доступ из справ.-правовой системы «КонсультантПлюс».

3 Согласно статистическим данным (URL: https://vsrf.ru/documents/statistics/27651/ (дата обращения: 23.05.2019)) в 2018 г. по апелляционным жалобам и представлениям было рассмотрено 1009 дел об оспаривании нормативных правовых актов. При этом в первом полугодии было рассмотрено 433 дела по соответствующей категории дел (URL: https://vsrf.ru/documents/statistics/27119/). Таким образом, во втором полугодии 2018 г. было рассмотрено 576 дел об оспаривании нормативных правовых актов.

${ }^{4}$ При этом при доверительной вероятности 95 \% и вероятности ошибки выборки $10 \%$ достаточным количеством размера выборки является анализ 82 случаев.

${ }^{5}$ Определение Верховного Суда РФ от 21 декабря 2018 г. № АКПИ18-827 ; Апелляционное определение Судебной коллегии по административным делам Верховного Суда РФ от 12 декабря 2018 г. № 92-АПГ18-10 ; Определение Судебной коллегии по административным делам Верховного Суда РФ от 25 июля 2018 г. № 44-АПГ18-10. Доступ из справ.-правовой системы «КонсультантПлюс». 
Отметим, что суды в своих решениях кратко описывают участие прокурора при рассмотрении и разрешении дел. Более того, в 25 случаях из 115 (21,7 \%) установить позицию прокурора, который вступил в дело для дачи заключения, невозможно ${ }^{6}$. В остальных случаях суды указывают либо «...заслушав... заключение прокурора Генеральной прокуратуры Российской Федерации..., полагавшего, что решение суда отмене не подлежит» ${ }^{7}$ либо «...заслушав... заключение прокурора Генеральной прокуратуры Российской Федерации..., полагавшей решение суда подлежащим отмене» ${ }^{8}$. Изложение решений судами не позволяет провести более глубокий анализ, например на предмет соотношения заключения прокурора с позицией истца, судом первой инстанции, судом апелляционной инстанции. Безусловно, такая позиция отрицательно сказывается не только на исследовательском потенциале решений суда, но и на правовой определенности судебных решений.

Далее перейдем к анализу сложившихся в процессуальной науке подходов по проблеме участия прокурора в делах об оспаривании нормативных правовых актов.

1. «Прокурор (в административном судопроизводстве ${ }^{9}$ ) призван гарантировать интересы частного лица как участника административного процесса, не наделенного властными полномочиями. Прокурор должен обеспечивать соблюдение прав и свобод человека и гражданина государственными органами и их должностными лицами» ${ }^{10}$.

${ }^{6}$ Например, в апелляционных определениях Судебной коллегии по административным делам Верховного Суда РФ от 14 декабря 2018 г. № 18-АПГ18-50 и № 18-АПГ18-49 написано: «Заслушав доклад судьи Верховного Суда Российской Федерации Горчаковой Е. В., заключение прокурора Генеральной прокуратуры Российской Федерации Гончаровой Н. Ю., Судебная коллегия по административным делам Верховного Суда Российской Федерации установила...». Других упоминаний о позиции прокурора в решении не содержится.

${ }^{7}$ См., например: Апелляционное определение Судебной коллегии по административным делам Верховного Суда РФ от 13 декабря 2018 г. № 53-АПГ18-27. Доступ из справ.-правовой системы «КонсультантПлюс».

8 См., например: Апелляционное определение Судебной коллегии по адми- 185 нистративным делам Верховного Суда РФ от 5 декабря 2018 г. № 42-АПГ18-10. Доступ из справ.-правовой системы «КонсультантПлюс».

${ }_{9}^{9}$ Судебная коллегия по административным спорам ВС РФ за 2018 г. как первая инстанция рассмотрела 254 административных дела, из них 202 были в рамках главы 21 КАС РФ, что составляет 80 \%. Учитывая данную статистику, а также соотношение производства в рамках главы 21 КАС РФ и административное судопроизводство как частное и общее, автор считает, что выводы относительно полномочий прокурора в административном судопроизводстве прямо применимы к полномочиям прокурора в рамках производства по делам об оспаривании нормативных правовых актов.

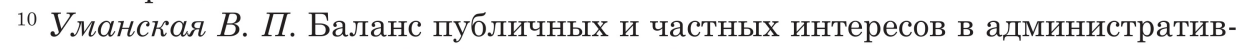
ном праве // Власть закона. 2017. № 1. С. 69-79. 


\section{Вестник ВГУ. Серия: Право}

Схожие идеи высказывались и другими учеными, например М. М. Закаряевой ${ }^{11}$, Н. А. Васильчиковой ${ }^{12}$ и др.

Полагаем, истоки такого понимания природы участия прокурора в административном судопроизводстве основываются, прежде всего, на ст. 1 Федерального закона «О прокуратуре Российской Федерации» ${ }^{13}$, где среди прочих целей деятельности прокуратуры РФ указана защита прав и свобод человека и гражданина. Для того чтобы прокурор имел возможность гарантировать интересы частного лица в процессе, частное лицо должно участвовать в процессе. Это означает, что речь идет либо о тех случаях, когда прокурор участвует в деле путем дачи заключения, либо о тех случаях, когда прокурор выступает в судебном процессе с исковым заявлением о защите интересов несовершеннолетнего или лица, признанного в установленном порядке недееспособным. При этом последняя категория дел в выборку решений, которая была сформирована для анализа, не попала. Учитывая специфику круга лиц, в интересах которого выступает прокурор, такие дела должны оставаться редкими в практике, а значит, критерии оценки деятельности прокурора требуют отдельной законодательной проработки.

Представляется, прокурор мог бы гарантировать интересы частного лица в тех случаях, когда он вступает в процесс для дачи заключения двумя способами. Во-первых, обладая знаниями действующего законодательства, он может представить некоторые дополнительные и имеющие существенное значение для дела аргументы в пользу административного истца либо отмечать отдельно уже сформулированные позиции административного истца, чтобы еще раз обратить внимание суда на позицию частного лица. Во-вторых, прокурор способен своими активными действиями обеспечить соблюдение гарантий прав и законных интересов частного лица. Проведенный анализ судебных решений позволяет сделать вывод о том, что позиция прокурора Генеральной прокуратуры РФ совпадала с позицией административного истца только в 57,0 \% случаев, при этом в суде первой инстанции позиция прокурора была аналогична ㄱ. позиции истца всего в 54,7 \% случаев. Соответственно, прокурор в своем заключении соглашается с позицией истца чуть больше, чем в 50 \% случаев. Такие действия, на наш взгляд, не могут квалифицироваться как

186 защита интересов частного лица в процессе. Анализ судебной практики также позволяет утверждать, что ни в одном из случаев нет упоминания о каких-либо активных действиях прокурора, направленных на защиту интересов частного лица, например попытке ходатайствовать о получении доказательств. Таким образом, анализ статистических данных опро-

${ }^{11}$ См.: Закаряева M. М. Проблемные вопросы участия прокурора при рассмотрении отдельных категорий дел особого производства // Законы России : опыт, анализ, практика. 2018. № 6. С. 74.

${ }^{12}$ См.: Васильчикова Н. А. Полномочия прокурора в гражданском судопроизводстве // Современное право. 2018. № 6. С. 99.

${ }^{13} \mathrm{O}$ прокуратуре Российской Федерации : федер. закон от 17 января 1992 г. № 2202-1. Доступ из справ.-правовой системы «КонсультантПлюс». 
вергает идею о том, что цель прокурора заключается в обеспечении защиты интересов частного лица по делам об оспаривании нормативных правовых актов. По всей видимости, прокурор в рамках судопроизводства по делам об оспаривании нормативных правовых актов не ассоциирует себя с защитой частных интересов, скорее пытается быть субъектом, который помогает судье отправлять правосудие путем дачи заключения.

2. «Прокурор должен гарантировать законность в административном судопроизводстве, осуществлять надзор за соблюдением законодательства судом и всеми участниками процесса» ${ }^{14}$.

Недостатки данного подхода состоят в следующем. Во-первых, законодательство не предлагает инструменты для реализации прокурором гарантии законности в административном судопроизводстве, ограничиваясь указанием на формы участия прокурора в судебном процессе. При этом Кодекс административного судопроизводства РФ ${ }^{15}$ (далее - КАС РФ) не предусматривает в рамках этих форм полномочия для прокурора по гарантии законности. Во-вторых, анализ судебных решений показывает, что не было ни одного случая, когда суды указывали бы на конкретные аргументы прокурора и давали им оценку - в них содержится только ссылка на то, что прокурор в своем заключении высказывает мнение о том, какое решение суд должен принять. По своей природе такое процессуальное действие ближе к правовому заключению по административному делу. При этом само по себе заключение прокурора не способствует, на наш взгляд, обеспечению гарантии законности в административном судопроизводстве, поскольку итоговое решение принимает суд. Данный вывод подтверждается, например, в 15,4 \% случаев, когда суд не соглашался с позицией прокурора Генеральной прокуратуры РФ, изложенной в заключении, и выносил противоположное решение. Тем не менее это не делает решение суда незаконным, а, значит, участие прокурора в административном деле никак не влияет на законность в административном судопроизводстве. При этом если рассмотреть действие прокурора в качестве дачи заключения по вопросам законности, то фактически можно выстроить следующую законодательную конструкцию. Вследствие того что экспертиза назначается по вопросам, требующим специальных знаний (п. 1 ст. 77 КАС РФ), соответственно, по делам об оспаривании нормативных актов законодательно устанавливается презумпция необходимости получения специальных знаний по вопросам законности, которые предоставляет прокурор в форме заключения. Установление такой презумпции означает, что фрактически законодатель считает, что судье в каждом процессе нужна помощь прокурора в связи с наличием у него специальных знаний по вопросам законности. Во-первых, такой подход однозначно увеличивает прямые судебные расходы (англ. direct costs

${ }^{14}$ Улинская В. П. Указ. соч. С. 69-79.

${ }^{15}$ Кодекс административного судопроизводства Российской Федерации : федер. закон от 8 марта 2015 г. № 21-Ф3. Доступ из справ.-правовой системы «КонсультантПлюс». 


\section{Вестник ВГУ. Серия: Право}

либо administrative costs) ${ }^{16}$, так как предполагает увеличение затрат на участие прокурора. При этом возможное уменьшение издержкки от ошибок (англ. error costs) ${ }^{17}$ не находит подтверждения в проведенном анализе судебных решений в связи с частым несовпадением позиций прокурора и судьи относительно итогового решения. Во-вторых, КАС РФ прямо указывает на то, что законность и справедливость при рассмотрении и разрешении судами административных дел обеспечиваются соблюдением положений, предусмотренных законодательством об административном судопроизводстве, точным и соответствующим обстоятельствам административного дела, правильным толкованием и применением законов и иных нормативных правовых актов, в том числе регулирующих отношения, связанные с осуществлением государственных и иных публичных полномочий, а также получением гражданами и организациями судебной защиты путем восстановления их нарушенных прав и свобод. Все способы обеспечения законности реализуются при непосредственном участии судьи. Прокурор при этом не может обладать по сравнению с судьей специальными знаниями по вопросам законности, которые требовали бы разъяснения в виде заключения прокурора. Таким образом, прокурор не может и не должен гарантировать законность в административном судопроизводстве.

3. «Участие прокурора в рассмотрении дел соответствующей категории, как в качестве лица, непосредственно обратившегося в суд в защиту тех или иных охраняемых законом интересов, ... подчеркивает возложенную государством особую роль на прокурора, которая следует из важнейшей цели функционирования прокуратуры Российской Федерации обеспечения защиты прав и свобод человека и гражданина» ${ }^{18}$.

Рассмотрим данную теорию. Прокурор выступил заявителем в 11 делах, что составляет 9,3 \% от общего числа рассмотренных дел. По результатам рассмотрения дел в суде апелляционной инстанции в 100 \% случаев суд вставал на сторону прокурора (суд первой инстанции соглашался

○ с позицией прокурора «всего» в 91 \% случаев). При этом прокурор, выㄱ ступая заявителем по данной категории дел, действительно обеспечивал защиту прав и свобод человека и гражданина. Как было указано, напри-

188 мер в Апелляционном определении Судебной коллегии по административным делам Верховного Суда РФ от 12 декабря 2018 г. № 92-АПГ18-10: «Прокурор Республики Тыва обратился в суд с административным иском о признании недействующими региональных норм ... считая, что их применение нарушает интересы Российской Федерации ввиду несоот-

${ }^{16}$ Cм.: Posner R. A. An Economic Approach to Legal Procedure and Judicial Administration // Journal of Legal Studies. 1973 (2). P. 399-458 ; Klerman D. M. The Economics of Civil Procedure // Annual Review of Law and Social Science. 2015 (11). P. 353-371.

${ }^{17}$ См.: Там же.

${ }^{18}$ Концевой $A$. В. Участие прокурора в гражданском судопроизводстве по делам, возникающим из публичных правоотношений : автореф. дис. ... канд. юрид. наук. М., 2013. 


\section{Административное право и процесс}

ветствия федеральному законодательству и наличия коррупциогенного фоктора» ${ }^{19}$.

Несомненно, статистический анализ позволяет сделать вывод об эффективности деятельности прокурора по делам об оспаривании нормативных правовых актов, так как суд практически всегда соглашался с требованиями прокурора о признании нормативного правового акта недействующим. При этом такая деятельность фактически является превентивной защитой частных прав и свобод граждан, поскольку признание недействующим такого акта означает, что впоследствии он не будет применяться на практике.

4. «Есть мнение, что специфика активной роли суда заключается в полной самостоятельности, что позволяет судье не предлагать сторонам представить дополнительные доказательства, но требовать от государственного органа (должностного лица) необходимые доказательства ${ }^{20}$.

Концепция, при которой прокурор участвует в процессе доказывания, во-первых, полностью опровергается настоящим исследованием, так как не было обнаружено ни одного упоминания о чем-то подобном в судебных решениях. Более того, краткость упоминаний в судебных решениях о деятельности прокурора в судебном процессе свидетельствует о том, что прокурор не ставит перед собой цель принимать участие в процедуре доказывания. Во-вторых, такая конструкция, если бы она активно использовалась, требует строгой законодательной регламентации, чтобы соответствовать принципам диспозитивности и состязательности процесса. На основании изученной совокупности судебных решений более чем в 40 \% случаев прокурор, занимая позицию государственного органа в споре, помогал бы собирать доказательства не гражданину, а государственному органу, что свидетельствовало бы об усилении разницы в процессуальных возможностях сторон. Таким образом, подобная ситуация противоречила бы принципу равноправия сторон административного судопроизводства.

5. Недостаток всех концепций, предполагающих, что прокурор осуществляет полномочия по обеспечению гарантий законности либо по обеспечению прав частных лиц, полагаем, состоит в следующем. Среди всех проанализированных дел обнаружено 39 дел, по которым можно по решению суда проанализировать как позицию прокурора в суде первой инстанции и суда субъекта РФ, так и позицию прокурора Генеральной прокуратуры РФ и позицию Верховного Суда РФ. В 30 случаях позиции прокурора в суде первой инстанции, прокурора Генеральной прокуратуры РФ и самого суда субъекта РФ совпадали. Однако в 9 случаях прокурор в суде первой инстанции и суд субъекта РФ занимали позицию, противоположную позиции истца. Верховный Суд РФ и прокурор Генеральной

19 Доступ из справ.-правовой системы «КонсультантПлюс».

${ }^{20}$ Егорова О. В. Производство по делам, возникающим из административно-правовых отношений, и гражданское судопроизводство // Журнал рос. права. 2001. № 5. C. 132-138. 


\section{Вестник ВГУ. Серия: Право}

прокуратуры РФ в этих случаях занимали позицию истца. Таким образом, в 23 \% случаев позиции прокурора Генеральной прокуратуры РФ и прокурора субъекта РФ не совпадали. С нашей точки зрения, значительный процент случаев, когда позиции прокурора в первой инстанции и прокурора Генеральной прокуратуры расходятся, не соответствует идее о том, что действия прокуратуры направлены на обеспечение соблюдения прав и законных интересов граждан. Какие именно действия - прокурора Генеральной прокуратуры РФ или прокурора субъекта РФ - следует считать действиями, направленными на обеспечение прав частных лиц? И способствуют ли достижению цели законности действия прокурора, учитывая то, что Верховный Суд РФ и суд субъекта РФ принимали решения в соответствии с заключением участвующих в делах прокуроров, а следовательно, суды приняли противоположные по своей сути решения? Кроме того, в чем именно состоит правовая природа заключения прокурора, и как этот институт коррелирует с процессуальной эффективностью?

Представляется, что на практике сложилась ситуация, при которой «гражданин может остаться полностью незащищенным не только перед административным ответчиком, но и перед «государственной машиной» - целой системой органов государственной власти в лице суда, прокурора и государственного органа, издавшего оспариваемый акт» ${ }^{21}$. Прокуроры выступают гораздо чаще на стороне государственных органов, чем Верховный Суд РФ. Например, прокурор Генеральной прокуратуры РФ согласился с позицией истца в 57,7 \% случаев, а Верховный Суд РФ принял сторону истца в 74 \% случаев. Таким образом, практически в 16,3 \% случаев у прокурора Генеральной прокуратуры РФ были веские основания занять позицию истца, но прокурор әтого не сделал. Учитывая данную тенденцию, административный истец часто в производстве выступает заведомо более слабой процессуальной стороной по сравнению с админиZ стративным ответчиком - государственным органом, что не может слу$\propto$ жить достижению главной цели по данной категории дел - признанию незаконных актов недействующими.

Полагаем, обозначенная выше проблема может быть решена двумя способами.

190 1. Участие прокурора в 9,3\% случаев как административного истца с заявлением о признании нормативного правового акта недействующим показывает, что прокурор не является главным интересантом признания нормативных правовых актов незаконными. В подавляющем большинстве случаев административным истцом, а следовательно, и главным интересантом признания акта недействующим выступают граждане. Отсюда следует вывод, что возможным решением проблем процессуального неравенства является переход к концепции «частного принуждения» ${ }^{22}$.

${ }^{21}$ Уманская В. П. Указ соч. С. 69-79.

${ }^{22}$ Emons W. Conditional versus contingent fees // University of Bern Discussion Paper. 2004. № 04.08 ; Shavell S. Economic Analysis of Litigation and the Legal Process // Harvard Law and Economics Discussion Paper. 2003. № 404. 


\section{Административное право и процесс}

Суть данной теории состоит в том, чтобы максимально возможно переложить ответственность за пресечение нарушений с государственных органов на частные субъекты и на юристов, которые представляют интересы частных лиц. Для сравнения, в зарубежных правовых системах, в частности США, данная теория закрепляет за гражданскими судебными процессами особую роль, выходя за рамки простого средства защиты гражданских прав. Такая политика «частного принуждения» создает систему поощрения частных субъектов, ищущих и исправляющих правонарушения без каких-либо рисков для такого частного лица, которое обратилось к «частному генеральному прокурору» 23 . В российском процессуальном законодательстве это представляет интерес с точки зрения закрепления возможности взыскания "гонорара успеха» с государственных органов в случае признания нормативного правового акта недействующим. Главная проблема для граждан при оспаривании нормативных правовых актов видится в необходимости из частных средств покрыть судебные расходы в надежде на последующую победу и возмещение судебных расходов. В такой ситуации в большинстве случаев рациональные граждане не имеют достаточных стимулов для обращения в суд. Одним из возможных решений этой проблемы является введение "гонорара успеха» по данной категории дел, когда граждане не должны будут вкладывать свои денежные средства для инициирования судебного процесса. Более того, такая система предполагает, что и потом граждане не несут риски потери денежных средств в результате отказа в исковых требованиях. Если государственный орган доказывает, что процедура принятия нормативного правового акта была соблюдена и нормативный правовой акт не противоречит акту, имеющему большую юридическую силу, то ни одна сторона не несет расходов. Если суд выносит решение в пользу частного лица, удовлетворяя заявленные требования, то государственный орган будет обязан выплатить "гонорар успеха» юристу, который представлял интересы частного лица. Таким образом, в любом случае частное лицо не претерпевает издержки в результате участия в процессе, а следовательно, стимулов для обращения в суды станет больше. При этом, полагаем, в данном случае минимизируются риски судебной волокиты в виде необоснованных исковых заявлений: юристы, которые будут подписывать соглашения, предусматривающие гонорар успеха, мотивированы на его получение, а это означает, что участвовать в делах по необоснованным требованиям такие юристы не будут.

2. В делах по оспариванию нормативных правовых актов, как показывает проведенный анализ, почти в 91 \% случаев спор возникает между

${ }^{23}$ Впервые словосочетание пошло из решения Верховного суда США по делу Newman v. Piggie Park Enterprises, Inc.: «Если он (представитель истцов по групповым искам) получает судебный запрет на осуществление действий, он делает это не только в частных интересах, но и как «частный генеральный прокурор», отстаивая политику, которую Конгресс считал наиболее приоритетной. (URL: http:// cdn.loc.gov/service/ll/usrep/usrep390/usrep390400/usrep390400.pdf (дата обращения: 23.05.2019)). 


\section{Вестник ВГУ. Серия: Право}

частным лицом и государственным органом. Представляется, стороны изначально находятся в неравном положении, поскольку, прежде всего, частное лицо, участвуя в таком административном деле, претерпевает денежные издержки для оплаты услуг представителя с высшим юридическим образованием. В данном случае прокурор должен рассматриваться в качестве инструмента по обеспечению баланса публичных и частных интересов. Иными словами, предлагаем закрепить обязанность совершения активных действий прокурора по получению доказательств в тех случаях, когда прокурор, вступивший в процесс с целью дачи заключения, полагает, что доказательство, которое еще не представлено в процесс, поможет защитить частные интересы.

Таким образом, на основании изложенного полагаем, что на современном этапе в российском процессуальном законодательстве особенно важно обеспечить разумное соотношение публичных и частных интересов, минимизировать возникающий дисбаланс ${ }^{24}$ и заложить механизмы преодоления коллизий. Представляется, что институт участия прокурора в административном судопроизводстве является одним из инструментов по достижению обозначенных задач.

${ }^{24}$ См.: Улманская В. П. Указ. соч.

Национальный исследовательский университет "Высшая школа эконолики»

Вифблянцев А. O., аспирант

E-mail: aoviflyantsev@gmail.com
National Research University "Higher School of Economics"

Viflyantsev A. O., Post-graduate Student

E-mail: aoviflyantsev@gmail.com 